\title{
A simulação e a otimização de parâmetros de dispositivos MOS planar e 3D usando o programa ADS
}

\section{Luana de Souza Melo (IC), José Alexandre Diniz (PQ)}

\section{Resumo}

A simulação de circuitos é uma ferramenta fundamental no desenvolvimento de projetos de circuitos integrados. Pela simulação é possível prever o comportamento dos circuitos e aperfeiçoá-los antes da sua fabricação, reduzindo os ciclos de projeto. Este trabalho tem como objetivo obter a extração de parâmetros de dispositivos MOS planar e 3D, com a maior precisão possível, visando o desenvolvimento de projetos de circuitos integrados. O projeto é dividido em três partes: i) conhecimento dos métodos para a extração de parâmetros de dispositivos MOS planar e tridimensional, ii) extração de parâmetros de dispositivos MOS planar e tridimensional, iii) simulação ADS com os parâmetros extraídos dos dispositivos MOS planar e tridimensional medidos.

Palavras Chave: caracterização, simulação, otimização.

\section{Introdução}

Uma maneira usual de se obter valores de parâmetros de modelos ou uma primeira aproximação dos valores é a partir de medidas obtidas em condições de operação nas quais o parâmetro tem um efeito predominante.

Neste trabalho são estudados os modelos utilizados no programa ADS. Os dispositivos MOS fabricados pelas tecnologias planar e tridimensional (3D) disponível no CCS são caracterizados eletricamente.

\section{Resultados e Discussão}

Os parâmetros dos modelos são determinados a partir dos dados da caracterização, com o objetivo de propor melhorias nas estruturas fabricadas e ajustar os modelos para uma simulação mais precisa.

Para uma simulação completa é necessária a extração de certos parâmetros elétricos de um dispositivo MOS. Estes parâmetros permitem dos modelos utilizados no simulador ADS.

Tabela 1. Caracterização transistores nMOS

\begin{tabular}{|l|l|l|}
\hline Lâmina & SOI & BULK \\
\hline Parâmetros & $\mathrm{L}=200 \mathrm{~W}=200$ & $\mathrm{~L}=200 \mathrm{~W}=200$ \\
\hline Tensão Early $(\mathrm{V})$ & -67 & -67 \\
\hline Rout $(\Omega)$ & $238 \mathrm{k}$ & $238 \mathrm{k}$ \\
\hline Gm & & \\
\hline $\mathrm{V}_{\text {TAX }}(\mathrm{p} / \mathrm{NBS})$ & 9 & - \\
\hline $\mathrm{V}_{\text {To }}$ na saturação & 0.2 & 0.2 \\
\hline
\end{tabular}

Figura 1. Curva IDSxVDS simulada

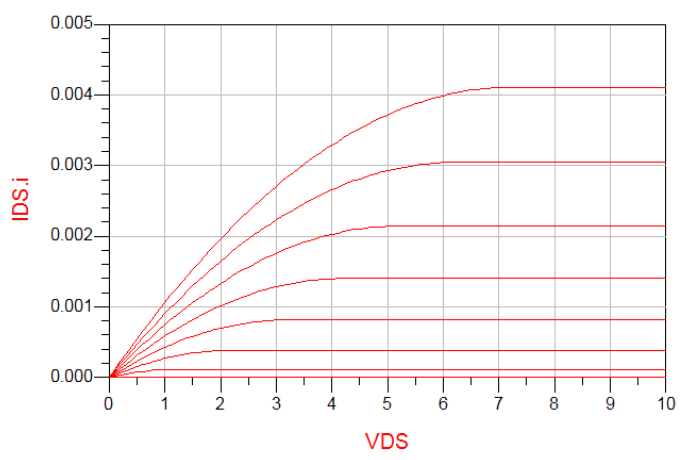

Figura 2. Curva IDSxVDS medida

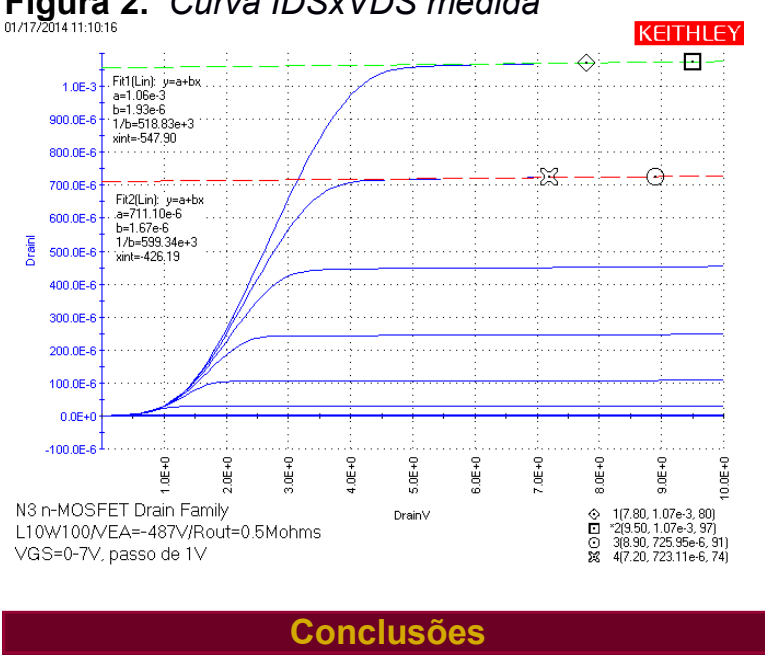

Através da análise da metodologia empregada neste trabalho, conclui-se que os métodos analíticos e computacionais são ferramentas fundamentais para determinação de parâmetros de dispositivos MOS, permitindo caracterizar os componentes com uma boa precisão e conseqüentemente reduzindo o efeito de erros e imprecisões. 